\title{
Pattern of allergic sensitization in chronic rhinitis: A 19-year retrospective study
}

Pongsakorn Tantilipikorn, Bannapuch Pinkaew, Kanokporn Talek, Paraya Assanasen, Triphoon Suwanwech, Chaweewan Bunnag

\begin{abstract}
Background: The pattern of allergic sensitization provides data for physicians to take appropriate care of allergic patients.

Objective: To analyze the long-term pattern of allergen skin prick test (SPT) sensitization at a single tertiary care hospital in Thailand.

Methods: Medical records of adult rhinitis patients during 1998 to 2017 were reviewed. Inclusion criteria were chronic rhinitis with positive SPT to at least one aeroallergen in the test panel. Outcome measures were SPT results, clinical symptoms, and their effect on patient quality of life (QoL). Descriptive statistics were used to demonstrate the pattern of sensitization. Multivariate linear regression was used to identify association between evaluated factors and patient QoL.

Results: Six thousand five hundred and seventeen adult patients were included in this study. Mean age was $36.4 \pm 13.8$ years. A majority of patients (59.4\%) had positive SPT, and $83.7 \%$ of those had polysensitization. Dermatophagoides pteronyssinus and sedge were the most common indoor (54.8\%) and outdoor allergens (37.7\%), respectively. Compared among the various periods of data collection over a 19-year period, there was no major change in the pattern of sensitization. Considering the most recent data from 2013-2017, the prevalence of sensitization increased from $66.8 \%$ to $73.7 \%(p<0.001)$. Clinical symptoms, except sneezing and allergen sensitization, affect QoL of chronic rhinitis patients $(p<0.001)$.
\end{abstract}

Conclusion: House dust mite and sedge are the most common indoor and outdoor allergens. There was no major change in the pattern of sensitization. Almost all allergic symptoms significantly affect QoL.

Key words: Allergy, skin prick test, allergic rhinitis, allergic sensitization, chronic rhinitis.

\section{Affiliation:}

Division of Rhinology \& Allergy, Department of Otorhinolaryngology, Faculty of Medicine Siriraj Hospital, Mahidol University, Bangkok, Thailand

\author{
Corresponding author: \\ Pongsakorn Tantilipikorn \\ Division of Rhinology \& Allergy, Department of Otorhinolaryngology \\ Faculty of Medicine Siriraj Hospital, Mahidol University \\ 2 Wanglang Road, Bangkoknoi, Bangkok 10700, Thailand \\ E-mail: pongsakorn.tan@mahidol.ac.th
}

\section{Introduction}

One of the most commonly observed diseases in the outpatient department is rhinitis. Immunoglobulin E (IgE)-mediated nasal inflammation plays a major role in chronic rhinitis. Effective management of allergic rhinitis (AR) requires a precise diagnosis which is the identification as inflammatory process of immunoglobulin $\mathrm{E}$ - mediated. In routine clinical practice, initial treatment by pharmacotherapy with avoidance of suspected causative allergens is the standard of care. ${ }^{1}$
When the initial treatment does not provide significant improvement, precise diagnosis of allergic rhinitis by skin prick test (SPT) is the principle modality. ${ }^{2}$

SPT is considered a standard diagnostic method because of its accuracy, reproducibility, and affordability. ${ }^{3}$ SPT requires good quality allergen extracts, and extracts that are appropriate for each geographic area. The pattern of SPT sensitization varies depending on the region. ${ }^{4-16}$ 
In addition to the characteristics of the pattern of allergic sensitization in each region, changes in the allergic sensitization pattern need to be periodically evaluated. Allergic sensitization patterns may change due to level of industrialization, climate change, and global warming, which may affect dissemination of allergens - especially pollen. ${ }^{17,18}$ Clinical profile, severity of quality of life (QoL), and comorbidities have been proposed as having association with SPT pattern. ${ }^{19-21}$

Allergic sensitization pattern of SPT vary according to area. For example, in Europe, the principle major burden al-

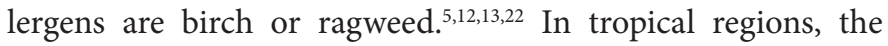
major allergen is house dust mite. ${ }^{4,7}$ Moreover, some allergens may also contribute for the clinical burden, such as molds and mosquito. ${ }^{23,24}$

In addition to differences in allergic sensitization pattern by geographical area, the allergic sensitization pattern may change over time. Several factors can affect a change in pattern, especially environmental effect. ${ }^{18}$ Allergic status also affects patient QoL. ${ }^{19-21}$ Updated allergic sensitization pattern data will help to guide effective allergy management. The objective of this article was to analyze the long-term pattern of allergen skin prick test (SPT) sensitization at a single center in Thailand, and to identify symptoms and other factors that significantly associate with patient QoL.

\section{Methods}

A retrospective chart review of patients that attended the outpatient allergy clinic of the Department of Otorhinolaryngology, Siriraj Hospital was conducted. Data was collected during 1998 to 2017. Patients with chronic rhinitis who had symptoms for more than one year and who had positive skin prick test (SPT) were included. Rhinitis was defined as the presence of 2 or more of the following symptoms: itching, sneezing, rhinorrhea, and/or nasal obstruction for more than 1 hour per day. ${ }^{25}$ Exclusion criteria were nasal polyposis, nasal tumors, and rhinitis medicamentosa.

The following data were extracted from the medical record: age, sex, result of SPT, presenting allergic symptoms, and comorbidities.

The SPT extracts were "Siriraj Allergen Vaccine (SAV)", which has been tested for Thai Food and Drug Agency (FDA) standard and allergenic potency (Greater Pharmaceutical Co. Ltd). ${ }^{26}$ The criterion of positive is size of wheal larger than $3 \mathrm{~mm}$ with accompanying flare. The extract panels were:
Dermatophagoides pteronyssinus, American cockroach (Periplaneta americana), cat, dog, mosquito (Aedes aegipti), mold (Aspergillus spp., Penicillium spp., Cladosporium spp.), Bermuda grass (Cynodon dactylon), para grass (Brachiaria mutica), sedge (Cyperaceae), careless weed (Amaranthus palmeri), and kapok (Ceiba pentandra). The positive and negative controls were histamine and normal saline, respectively.

The pattern of allergic sensitization of each allergen was displayed as percentage of subjects who have positive skin reaction comparing to the number of subjects who have been SPT. The sensitization of SPTs was categorized into monosensitization and polysensitization (positive SPT for equal to or more than two allergens). The pattern of allergic sensitization was also grouped into indoor allergen or outdoor allergen sensitization.

To determine their effect on QoL, most recent clinical data from the 2013 to 2017 period were analyzed. That data set was also analyzed to compare the prevalence rate of sensitization. A questionnaire for allergic rhinitis, which was validated by our team, was used to determine QoL. ${ }^{21}$

\section{Statistical analysis}

Data analysis was performed using PASW Statistics (SPSS Inc, Chicago, IL, USA). Demographic data and other categorical variables are presented. Data are presented as frequency and percentage for categorical data, and as mean plus or minus standard deviation and range for continuous data. Clinical symptoms and SPT sensitization were evaluated for association with QoL using linear regression analysis. Factors with a $p$-value less than 0.2 in univariate analysis were included in multivariate analysis by stepwise method. The results of multivariate analysis are shown as regression coefficient and 95\% confidence interval. To compare the prevalence of allergic sensitization during 2013 to 2017, 'Chi-square for trend' method was used. A $p$-value less than 0.05 was considered statistically significant.

The local ethical committee approved this study with COA \# 242/2559(EC1).

\section{Results}

Demographic and clinical data are shown in Table 1. The clinical symptoms of subjects with SPT positive (AR) were statistically difference from the subjects with SPT negative except the perennial symptoms. The onset of rhinitis and

Table 1. Demographic and clinical characteristics of patients during 1998-2017 $(\mathrm{N}=6,517)$

\begin{tabular}{lcccc}
\multicolumn{1}{c}{ Characteristics } & $\mathbf{n}(\%)$ & Skin test positive & Skin test negative & $p$-value \\
\hline Age (years) & & & \\
Mean (SD) & $36.4(13.8)$ & 34.3 & 39.0 & $<0.001$ \\
Range & 7 to 81 & 7 to 78 & 7 to 81 & \\
Sex & & & \\
Male & $2,359(36.2 \%)$ & $1,394(59.1 \%)$ & $965(40.9 \%)$ & $<0.001$ \\
Female & $4,158(63.8 \%)$ & $2,171(52.2 \%)$ & $1,987(47.8 \%)$ & $<0.001$ \\
Allergic sensitization & & $3,871(59.4 \%)$ & $2,646(40.6 \%)$ & $<0.001$ \\
\hline
\end{tabular}


Table 1. (Continued)

\begin{tabular}{lcccc|}
\hline \multicolumn{1}{|c}{ Characteristics } & $\mathbf{n}(\%)$ & Skin test positive & Skin test negative & $\boldsymbol{p}$-value \\
\hline Polysensitization & & $3,240(83.7 \%)$ & & \\
\hline Itchy nose & $3,788(58.1 \%)$ & $2,354(60.8 \%)$ & $1,434(54.2 \%)$ & $<0.001$ \\
\hline Sneezing & $3,352(51.4 \%)$ & $2,101(54.3 \%)$ & $1,251(47.3 \%)$ & $<0.001$ \\
\hline Running nose & $4,146(63.6 \%)$ & $2,593(67.0 \%)$ & $1,553(58.7 \%)$ & $<0.001$ \\
\hline Stuffy nose & $4,106(63 \%)$ & $2,524(65.2 \%)$ & $1,582(59.8 \%)$ & $<0.001$ \\
\hline Itchy eye & $2,825(43.3 \%)$ & $1,835(47.4 \%)$ & $990(37.4 \%)$ & $<0.001$ \\
\hline Cough & $2,081(31.9 \%)$ & $1,142(29.5 \%)$ & $939(35.5 \%)$ & $<0.001$ \\
\hline Snoring & $1,851(28.4 \%)$ & $1,049(27.1 \%)$ & $802(30.3 \%)$ & 0.005 \\
\hline Perennial symptoms & $2,732(41.9 \%)$ & $1,618(41.8 \%)$ & $1,114(42.1 \%)$ & 0.80 \\
\hline Family history of atopy & $3,214(49.3 \%)$ & $1,978(51.1 \%)$ & $1,236(46.7 \%)$ & $<0.001$ \\
\hline Onset of rhinitis (years) & 28.37 & 25.4 & 35.3 & $<0.001$ \\
\hline Quality of Life (SD) & $72.8(17.6)$ & $72.8(18.0)$ & $73.0(16.0)$ & 0.78 \\
\hline
\end{tabular}

Table 2. Pattern of allergen sensitization during 1998-2017 $(\mathrm{N}=3,871)$

\begin{tabular}{|c|c|c|c|}
\hline \multicolumn{4}{|c|}{ Years 1998-2017 $(\mathrm{N}=3,871)$} \\
\hline $\begin{array}{l}\text { Years 1998-2004 } \\
\quad(n=1,197)\end{array}$ & $\begin{array}{l}\text { Years 2005-2009 } \\
\quad(\mathrm{n}=995)\end{array}$ & $\begin{array}{l}\text { Years 2010-2012 } \\
\quad(\mathrm{n}=779)\end{array}$ & $\begin{array}{l}\text { Years 2013-2017 } \\
\quad(n=900)\end{array}$ \\
\hline \multicolumn{4}{|l|}{ Top 3 Indoor Allergens } \\
\hline 1. Mite $40.1 \%(n=994)$ & 1. Mite $50.6 \%(n=696)$ & 1. Mite $59.3 \%(\mathrm{n}=753)$ & 1. Mite $44.1 \%(\mathrm{n}=614)$ \\
\hline 2. Cockroach $11.4 \%(n=283)$ & 2. $\operatorname{Dog} 37.4 \%(n=515)$ & 2. Cockroach $42.5 \%(n=539)$ & 2. Cockroach $35.0 \%(n=488)$ \\
\hline 3. $\operatorname{Dog} 8.2 \%(n=203)$ & 3. Cockroach $31.0 \%(n=427)$ & 3. Cat $40.4 \%(n=513)$ & 3. Cat $32.5 \%(n=453)$ \\
\hline \multicolumn{4}{|l|}{ Top 3 Outdoor Allergens } \\
\hline 1. Sedge $18.5 \%(n=458)$ & 1. Sedge $38.1 \%(n=487)$ & 1. Sedge $47.4 \%(n=604)$ & 1. Sedge $38.1 \%(n=386)$ \\
\hline 2. Bermuda $13.64 \%(n=337)$ & 2. Para grass $36.3 \%(n=482)$ & 2. Para grass $44.6 \%(n=584)$ & 2. Bermuda $30.9 \%(n=408)$ \\
\hline 3. Para grass $11.14 \%(n=275)$ & 3. Bermuda $36.0 \%(n=446)$ & 3. Bermuda $41.5 \%(n=548)$ & 3. Para grass $26.4 \%(n=354)$ \\
\hline
\end{tabular}

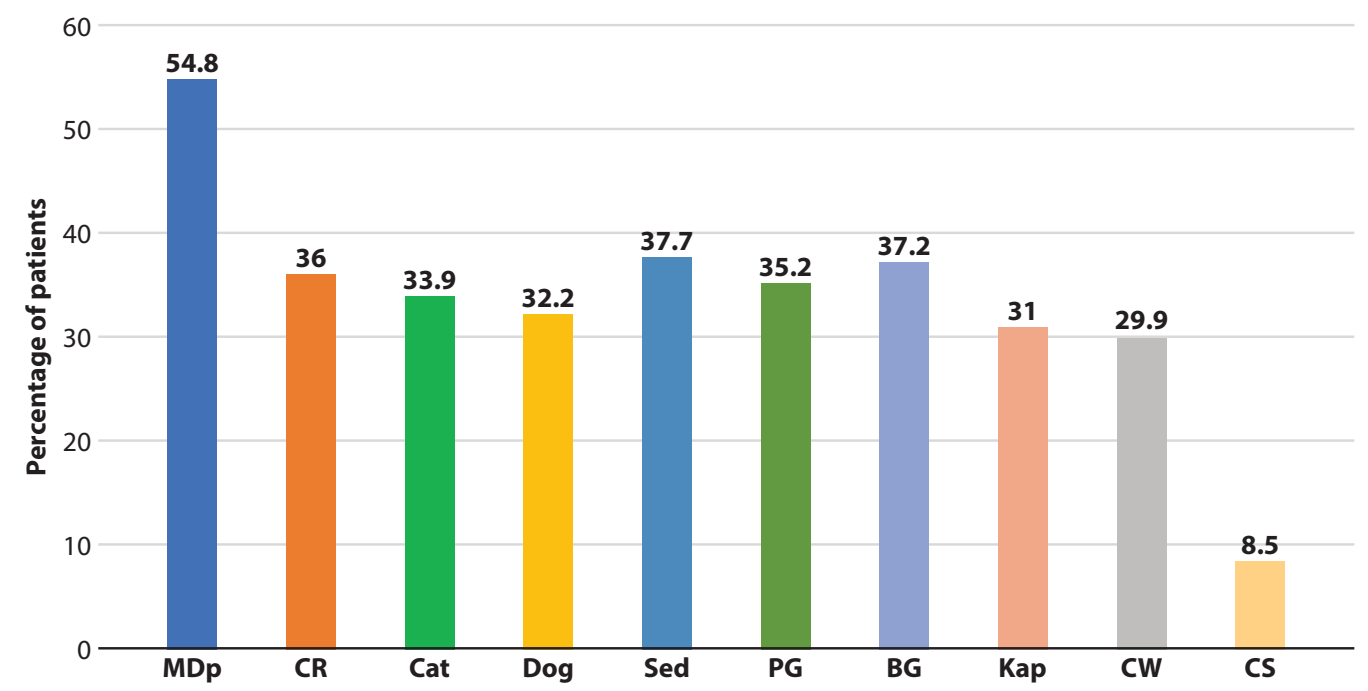

Figure 1. Pattern of allergen sensitization during 19 years (1998-2017)

Abbreviations: MDp (Mite/Dermatophagoides pteronyssinus), CR (Cockroach), Sed (Sedge), PG (Para grass), BG (Bermuda grass), Kap (Kapok), CW (Careless weed), CS (Cladosporium spp.). 
family history of atopy in AR group are statistically difference from NAR. The pattern of allergic sensitization stratified by time period is shown in Table 2. All patients were positive for at least one allergen. Dermatophagoides pteronyssinus and sedge were the most common indoor (54.8\%) and outdoor allergens (37.7\%), respectively. (Figure 1)

During the most recent period (2013 to 2017), the data from 1,457 chronic rhinitis patients were used for inferential statistical analysis. The mean age was 37.2 years, and the majority of patients were female. Mite with cockroach is the common pattern of polysensitization.

During the most recent five-year period, the prevalence of overall allergen sensitization significantly increased from $66.8 \%$ to $75.7 \%$ (chi-square test for trend: $p=0.006$ ). The prevalence of indoor allergen sensitization also significantly increased from $59.6 \%$ to $72.3 \%$ (chi-square test for trend:
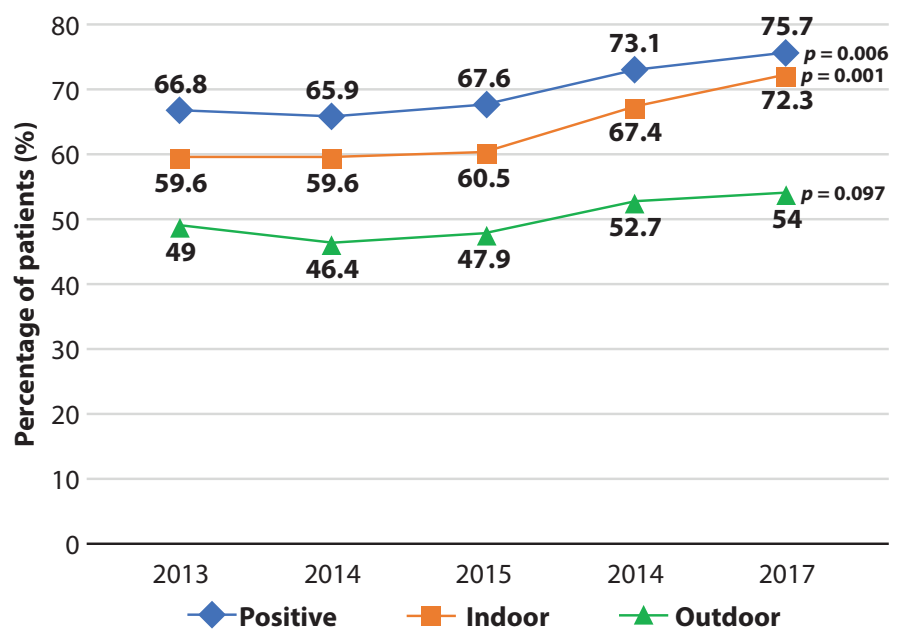

Figure 2. Trend change of allergen sensitization during 2013-2017 $(\mathrm{N}=1,457)$

\section{A}

60
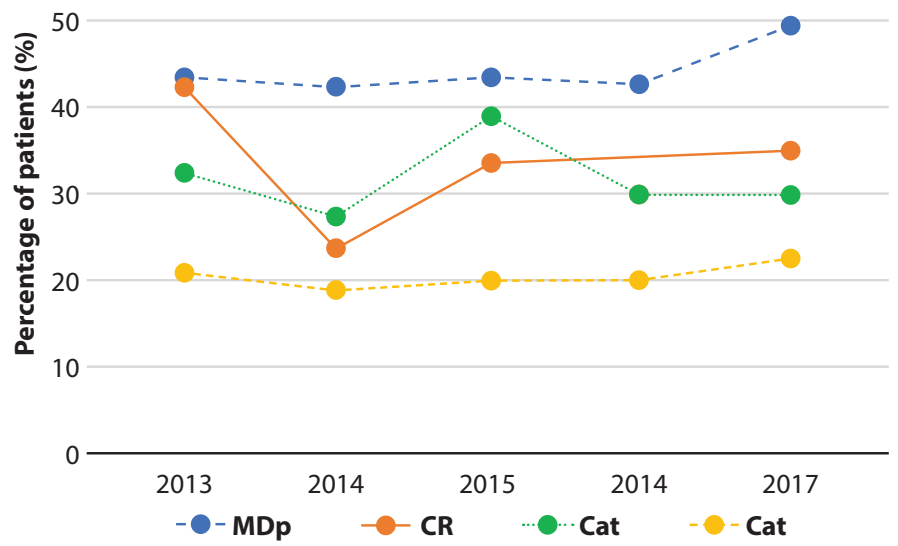

$p=0.001)$. The prevalence of outdoor allergen sensitization did not change significantly (chi-square test for trend: $p=$ 0.097). (Figure 2)

Figures 3 show the trend of allergic sensitization pattern for individual allergens during the most recent five-year period. Mite was also found to be the most common indoor sensitization (44.1\%), and sedge was the most common outdoor sensitization (31.3\%). The sensitization of fungal allergens was less than the sensitizations from the other groups.

During that time period, the trend changes show house dust mite as the most common sensitization. Cockroach and dog alternately manifested as the second and the third most common allergic sensitization. Dog remained as the fourth most common indoor sensitization. For the outdoor allergens, sedge remained the most common sensitization during most years. The sensitization of careless weed decreased, and the sensitization of para grass remained stable.

Regarding the issue of burden of AR symptoms, the correlation between mean wheal diameter of SPT and rhinitis symptoms was determined by Pearson's correlation coefficient. Only the degree of wheal of mite and dog sensitization showed statistical significant with AR symptoms $(p<0.0001$, $r=0.1$ ), but there was no statistical significant with the other allergen. Clinical characteristics, sex, and sensitization status were evaluated to identify factors that significantly associate with patient QoL. Univariate analysis revealed clinical symptoms and sex to be statistically significantly related to QoL, but no significant relationship was found for sensitization. Multiple linear regression analysis revealed that all rhinitis symptoms, except sneezing, adversely affect patient QoL (Table 3). Sensitization also did not remain statistically significant in multivariate analysis. Itchy nose and itchy eyes were the symptoms that had the most pronounced effect on QoL, with regression coefficients of 5.08 (95\% confidence interval [CI]: 3.18-6.98) and 5.2 (95\% CI: 3.29-7.10), respectively.

\section{B}

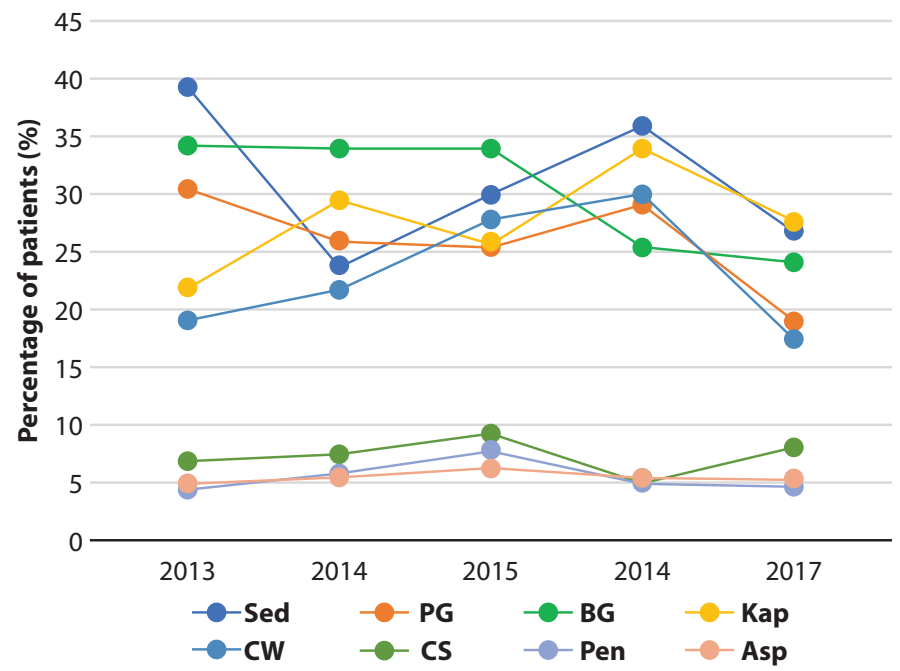

Figure 3. Trend change of indoor (Figure 3A), outdoor allergens and molds (Figure 3B) during 2013-2017 ( $\mathrm{N}=1,457$ ) Abbreviations: MDp (Mite/Dermatophagoides pteronyssinus), CR (Cockroach), Sed (Sedge), PG (Para grass), BG (Bermuda grass), Kap (Kapok), CW (Careless weed), CS (Cladosporium spp.), Pen (Penicillium spp.), Asp (Aspergillus spp.). 
Table 3. Factors that affect patient quality of life (QoL) $(N=1,457)$

\begin{tabular}{|c|c|c|c|c|}
\hline \multirow[b]{2}{*}{ Factor } & \multirow[b]{2}{*}{ n } & \multirow{2}{*}{$\begin{array}{c}\text { Univariate analysis } \\
\text { p-value }\end{array}$} & \multicolumn{2}{|c|}{ Multivariate linear regression } \\
\hline & & & $\begin{array}{l}\text { Regression coefficient } \\
\qquad(95 \% \mathrm{CI})\end{array}$ & $p$-value \\
\hline \multicolumn{5}{|l|}{ Sex } \\
\hline Male & 524 & & & \\
\hline Female & 933 & $<0.001^{\star}$ & $2.00(0.13: 3.86)$ & $0.036^{*}$ \\
\hline \multicolumn{5}{|l|}{ Ichy nose } \\
\hline No & 645 & & & \\
\hline Yes & 785 & $<0.001^{*}$ & $5.08(3.18: 6.98)$ & $<0.001^{*}$ \\
\hline \multicolumn{5}{|l|}{ Sneezing } \\
\hline No & 735 & & & \\
\hline Yes & 695 & $<0.001^{\star}$ & - & \\
\hline \multicolumn{5}{|l|}{ Rhinorrhea } \\
\hline No & 553 & & & \\
\hline Yes & 877 & $<0.001^{*}$ & $2.44(0.53: 4.34)$ & $<0.001^{*}$ \\
\hline \multicolumn{5}{|c|}{ Nasal congestion } \\
\hline No & 546 & & & \\
\hline Yes & 884 & $<0.001^{\star}$ & $4.12(2.32: 5.92)$ & $<0.001^{*}$ \\
\hline \multicolumn{5}{|l|}{ Ichy eyes } \\
\hline No & 825 & & & \\
\hline Yes & 605 & $<0.001^{*}$ & $5.20(3.29: 7.10)$ & $<0.001^{\star}$ \\
\hline \multicolumn{5}{|l|}{ Cough } \\
\hline No & 417 & & & \\
\hline Yes & 1013 & $<0.001^{*}$ & $3.22(1.33: 5.11)$ & $0.001^{*}$ \\
\hline \multicolumn{5}{|l|}{ Snoring } \\
\hline No & 404 & & & \\
\hline Yes & 1026 & $<0.001^{\star}$ & $3.50(1.59: 5.42)$ & $<0.001^{*}$ \\
\hline \multicolumn{5}{|c|}{ Perennial symptoms } \\
\hline No & 653 & & & \\
\hline Yes & 777 & $<0.001^{*}$ & $3.79(2.07: 5.52)$ & $<0.001^{*}$ \\
\hline \multicolumn{5}{|l|}{ Weather change } \\
\hline No & 413 & & & \\
\hline Yes & 1,017 & $<0.001^{\star}$ & $3.09(1.11: 5.06)$ & $0.002^{*}$ \\
\hline \multicolumn{5}{|l|}{ Sensitization } \\
\hline Negative & 434 & & & \\
\hline Positive & 996 & 0.742 & - & \\
\hline
\end{tabular}




\section{Discussion}

The main finding of this 19-year study (1998 to 2017) is that house dust mite and sedge remain the most common indoor and outdoor allergens. The second and third most common indoor allergens, which are cockroach and cat. Mosquito has been reported for the allergens of dermatologic manifestations in in the study of allergy clinic of Internal Medicine Department. ${ }^{23}$ Its contribution for the respiratory allergic symptoms remains questionable. So, we did not display the sensitization of mosquito in the analysis chart. Sedge, para grass, and Bermuda grass were the most common allergens in our outdoor allergens group. A recent study from another tertiary care center in Thailand reported the most common outdoor allergens to be Bermuda grass and timothy grass. ${ }^{6}$

Regarding the associated symptoms, ophthalmologic symptoms were found in $43.3 \%$ of patients, which is consistent with the finding from the aforementioned study from Thailand. We also found that $28.4 \%$ of patients suffer from snoring, and that $31.9 \%$ of patients have coughing symptoms. This finding supports the concept of one airway - one disease. $^{27}$

In order to quantitatively compare the trend of sensitization prevalence, we utilized the data from the latest five-year period (2013 to 2017). This data set was also used to determine the effect of clinical symptoms and allergic status on patient QoL.

During the 2013 to 2017 period, the percentage of sensitization showed a statistically significant increase from $66.8 \%$ to $75.7 \%$. The sensitization pattern of change was found to be greater in indoor allergens $(59.6 \%$ to $72.3 \%)$ than in outdoor allergens ( $49 \%$ to $54 \%$ ). This finding supports the global trend of epidemiologic study that suggests that allergic sensitization is affected by environmental factors, such as increasing level of industrialization, climate change, and global warming, which may affect dissemination of allergens. ${ }^{13,18}$

House dust mite remained the most common indoor allergen during the 2013 to 2017 period, and sedge remained the most common in the outdoor group. Careless weed assumed a lessor role during the recent period in our study. A study from Singapore reported Bahia grass to be the most common allergen. ${ }^{28} \mathrm{~A}$ recent study from the Philippines found Bermuda grass to be the most common outdoor allergen. ${ }^{7}$ Cladosporium spp. was the most common in our fungus group. A report from Poland showed Alternaria spp. to be the most common, and Cladosporium spp. to be the second most common. ${ }^{24}$

We used linear regression multivariate analysis to determine the effect of clinical characteristics and sensitization status on patient quality of life. Similar to previous reports, all of the clinical parameters significantly affect patient QoL in univariate linear regression. ${ }^{21,29}$ However, sneezing symptom did not remain significantly associated with QoL in multivariate analysis. Also and surprisingly, sensitization status did not show significant association with QoL. This may be explained by the fact that some patients that have rhinitis symptoms for many years can have either a negative or positive skin prick test. Moreover, there may be a subgroup of patients with local IgE (local allergic rhinitis) who have a negative skin prick test. ${ }^{30}$ Regarding the finding of sex as the factor that affects QoL, the finding can also be postulated by the tendency of health awareness of female comparing to male especially when determining the effect of allergic symptoms to QoL.

The notable limitation of this study is its retrospective design. Consistent with this limitation, some data were found to be missing or incomplete. However, all SPT procedures were performed according to uniform technique by trained technicians. Importantly, this study had a large enough sample size to perform multivariate linear regression analysis to identify significant associations between evaluated factors and patient QoL.

\section{Conclusion}

The results of this study revealed an increasing prevalence of allergy sensitization. The increase is more pronounced in indoor allergens than in outdoor allergens. House dust mite remains the most comment indoor allergen, and sedge is the most common outdoor allergen. A change in sensitization pattern was found for cockroach, bermuda grass, and para grass. Patient quality of life is affected by all clinical symptoms, except sneezing and allergen sensitization.

\section{Acknowledgements}

The authors gratefully acknowledge Ms. Julaporn Poolium for statistical analysis, and Mrs. Jeerapa Kerdnoppakhun for manuscript preparation.

\section{Conflict of interest declaration}

All authors declare no personal or professional conflicts of interest relating to any aspect of this study.

\section{Funding disclosure}

This study was funded by a grant from the Faculty of Medicine Siriraj Hospital Research Fund.

\section{References}

1. Bousquet J, Schunemann HJ, Fonseca J, Samolinski B, Bachert C, Canonica GW, et al. MACVIA-ARIA Sentinel NetworK for allergic rhinitis (MASK-rhinitis): the new generation guideline implementation. Allergy. 2015;70(11):1372-92

2. Scadding GK, Kariyawasam HH, Scadding G, Mirakian R, Buckley RJ, Dixon T, et al. BSACI guideline for the diagnosis and management of allergic and non-allergic rhinitis (Revised Edition 2017; First edition 2007). Clin Exp Allergy. 2017;47(7):856-89.

3. Bousquet J, Heinzerling L, Bachert C, Papadopoulos NG, Bousquet PJ, Burney PG, et al. Practical guide to skin prick tests in allergy to aeroallergens. Allergy. 2012;67(1):18-24.

4. Dey D, Mondal P, Laha A, Sarkar T, Moitra S, Bhattacharyya S, et al. Sensitization to Common Aeroallergens in the Atopic Population of West Bengal, India: An Investigation by Skin Prick Test. Int Arch Allergy Immunol. 2019;178(1):60-5.

5. Ahmed H, Ospina MB, Sideri K, Vliagoftis H. Retrospective analysis of aeroallergen's sensitization patterns in Edmonton, Canada. Allergy Asthma Clin Immunol. 2019;15:1-6.

6. Oncham S, Udomsubpayakul U, Laisuan W. Skin prick test reactivity to aeroallergens in adult allergy clinic in Thailand: a 12-year retrospective study. Asia Pac Allergy. 2018;8(2):e17.

7. Navarro-Locsin CG, Lim-Jurado M. Aeroallergen sensitization and associated comorbid diseases of an adult Filipino population with allergic rhinitis. Asia Pac Allergy. 2018;8(3):e25. 
8. Lou H, Ma S, Zhao Y, Cao F, He F, Liu Z, et al. Sensitization patterns and minimum screening panels for aeroallergens in self-reported allergic rhinitis in China. Sci Rep. 2017;7(1):9286.

9. Ozkaya E, Sogut A, Kucukkoc M, Eres M, Acemoglu H, Yuksel H, et al. Sensitization pattern of inhalant allergens in children with asthma who are living different altitudes in Turkey. Int J Biometeorol. 2015;59(11):1685-90.

10. Farrokhi S, Gheybi MK, Movahed A, Tahmasebi R, Iranpour D, Fatemi A, et al. Common aeroallergens in patients with asthma and allergic rhinitis living in southwestern part of Iran: based on skin prick test reactivity. Iran J Allergy Asthma Immunol. 2015;14(2):133-8.

11. Mims JW. Epidemiology of allergic rhinitis. Int Forum Allergy Rhinol. 2014;4 Suppl 2:S18-20.

12. Valero A, Justicia JL, Anton E, Dordal T, Fernandez-Parra B, Lluch M, et al. Epidemiology of allergic rhinitis caused by grass pollen or house-dust mites in Spain. Am J Rhinol Allergy. 2011;25(4):e123-8.

13. Singh K, Axelrod S, Bielory L. The epidemiology of ocular and nasal allergy in the United States, 1988-1994. J Allergy Clin Immunol. 2010; 126(4):778-83.e6.

14. Li J, Sun B, Huang Y, Lin X, Zhao D, Tan G, et al. A multicentre study assessing the prevalence of sensitizations in patients with asthma and/or rhinitis in China. Allergy. 2009;64(7):1083-92.

15. Yuen AP, Cheung S, Tang KC, Ho WK, Wong BY, Cheung AC, et al. The skin prick test results of 977 patients suffering from chronic rhinitis in Hong Kong. Hong Kong Med J. 2007;13(2):131-6.

16. Arbes SJ Jr, Gergen PJ, Elliott L, Zeldin DC. Prevalences of positive skin test responses to 10 common allergens in the US population: results from the third National Health and Nutrition Examination Survey. J Allergy Clin Immunol. 2005;116(2):377-83.

17. Mady LJ, Schwarzbach HL, Moore JA, Boudreau RM, Tripathy S, Kinnee E, et al. Air pollutants may be environmental risk factors in chronic rhinosinusitis disease progression. Int Forum Allergy Rhinol. 2018;8(3): 377-84.

18. D’Amato G, Vitale C, Rosario N, Neto HJC, Chong-Silva DC, Mendonca F, et al. Climate change, allergy and asthma, and the role of tropical forests. World Allergy Organ J. 2017;10(1):11

19. Tantilipikorn P, Saisombat P, Phonpornpaiboon P, Pinkaew B, Lermankul W, Bunnag C. Minimal clinically important difference for the rhinoconjunctivitis quality of life questionnaire in allergic rhinitis in Thai population. Asia Pac Allergy. 2019;9(1):e6.
20. Bunnag C, Leurmarnkul W, Jareoncharsri P, Tunsuriyawong P, Assanasen P, Pawankar R. Quality of life assessment in Thai patients with allergic rhinoconjunctivitis using the SF-36 questionnaire (Thai version). Rhinology. 2005;43(2):99-103.

21. Bunnag C, Leurmarnkul W, Jareoncharsri P, Ungkanont K, Tunsuriyawong $\mathrm{P}$, Kosrirukvongs $\mathrm{P}$, et al. Development of a health-related quality of life questionnaire for Thai patients with rhinoconjunctivitis. Asian Pac J Allergy Immunol. 2004;22(2-3):69-79.

22. Rueff F, Przybilla B, Walker A, Gmeiner J, Kramer M, Sabanes-Bove D, et al. Sensitization to common ragweed in southern Bavaria: clinical and geographical risk factors in atopic patients. Int Arch Allergy Immunol. 2012;159(1):65-74.

23. Manuyakorn W, Itsaradisaikul S, Benjaponpitak S, Kamchaisatian W, Sasisakulporn C, Jotikasthira W, et al. Mosquito allergy in children: Clinical features and limitation of commercially-available diagnostic tests. Asian Pac J Allergy Immunol. 2017;35(4):186-90.

24. Kolodziejczyk K, Bozek A. Clinical Distinctness of Allergic Rhinitis in Patients with Allergy to Molds. Biomed Res Int. 2016;2016: 3171594.

25. Brozek J, Bousquet J, Baena-Cagnani C, Bonini S, Canonica G, Casale T, et al. Allergic Rhinitis and its Impact on Asthma (ARIA) guidelines: 2010 Revision. J Allergy Clin Immunol. 2010;126:466-76.

26. Visitsunthorn N, Bunnag C, Pacharn P, Assanasen P, Jirapongsananuruk O, Thongngarm T, et al. In-vivo allergenic potency of Siriraj Mite Allergen Vaccine (SMAV) comparing with standardized vaccine in mite-sensitive patients. Asian Pac J Allergy Immunol. 2011;29(1):50-6.

27. Feng $\mathrm{CH}$, Miller MD, Simon RA. The united allergic airway: connections between allergic rhinitis, asthma, and chronic sinusitis. Am J Rhinol Allergy. 2012;26(3):187-90.

28. Lim MY, Leong JL. Allergic rhinitis: evidence-based practice. Singapore Med J. 2010;51(7):542-50.

29. Bunnag C, Jareoncharsri P, Tantilipikorn P, Vichyanond P, Pawankar R. Epidemiology and current status of allergic rhinitis and asthma in Thailand -- ARIA Asia-Pacific Workshop report. Asian Pac J Allergy Immunol. 2009;27(1):79-86.

30. Tantilipikorn P, Siriboonkoom P, Sookrung N, Thianboonsong A, Suwanwech T, Pinkaew B, et al. Prevalence of local allergic rhinitis to Dermatophagoides pteronyssinus in chronic rhinitis with negative skin prick test. Asian Pac J Allergy Immunol [Preprint]. 2019 [cited 2019 Jun 30]. Available form: http://apjai-journal.org/wp-content/upload/2019/04/ AP-170918-0408.pdf 